\title{
Lexical Bundles and the Construction of an Academic Voice in Business Writing
}

\author{
Malek Mhedhbi \\ E-mail:mhedhbi_malek@yahoo.fr \\ Doi:10.7575/aiac.alls.v.5n.6p.1 \\ Received: 24/07/2014 \\ URL: http://dx.doi.org/10.7575/aiac.alls.v.5n.6p.1 \\ Accepted: 20/09/2014
}

\begin{abstract}
Most previous studies on disciplinary academic writing focused on the structures in research articles or linguistic realizations of each move (Lau, 2004; Hyland, 2000). Few have been conducted to address the interpersonal aspect of disciplinary discourse texts. The purpose of this study was to measure the effect of lexical bundles' (LBs) awareness on writing enhancement of high-intermediate ESP learners. To this aim, 16 male and female learners studying at Tunis Business School were selected. Their grades of previous academic years underlined the homogeneity of the participants. They were randomly divided into experimental and control groups. The control group was taught based on the conventional approaches of writing. The experimental group received a treatment of LBs awareness in the writing of a credible academic prose. The design of the study was based on four phases respectively a pre-test, a treatment, a posttest and a questionnaire. The pre-test was constituted of two short parts aiming at examining the rhetorical features of the participants' writings particularly their knowledge of LBs. Then the treatment phase which comprised three tasks in teaching LBs. After that, a post-test was administrated in an attempt to examine the effect of the treatment on the participants' output. Next, an 8-item evaluation questionnaire, including an open-ended question, was distributed to elicit information about the students' attitudes towards the techniques used to raise their awareness of LBs' use. The findings revealed that there was a significant difference between the writing scores and LBs' use among the participants in the control and experimental groups. The results of the questionnaire also demonstrated students' positive perceptions towards the usefulness of the LBs treatment tasks.
\end{abstract}

Keywords: Lexical bundles, business writing, consciousness-raising tasks

\section{Introduction}

Corpus-based language use such as Biber et al., (1999), Cortes (2004; 2006), Hyland (2008) and Simpson \& Ellis (2010) have provided insights into the functional significance of highly frequent recurrent sequences of words particularly Lexical Bundles (LBs) in various disciplinary discourses. In this respect, Scott \& Tribble (2006) recognize the usefulness of LBs for understanding how expert texts are produced and how they are different from the output of apprentice language users. In addition, Hyland (2008) argues that multi-word structures (i.e LBs) are components of fluent linguistic production and key factors of language learning. He further claims that learning LBs used in a discipline-specific discourse contributes to gaining communicative competence within that field of study. Therefore, many linguistics suggest the need for LBs identification and teaching so as to help learners acquire the specific rhetorical practices of the texts they asked to write. To accomplish this, students should be familiar with LBs used in academic writing in order to create what Hyland calls "professionally acceptable persona" i.e students' voice reflected in the rhetorical style of writing. In this vein, the present study attempt to investigate the effect of teaching recurrent LBs on developing students' writing proficiency through the use of consciousness-raising tasks.

\subsection{Research Questions}

1) Do consciousness-raising tasks have any significant effect on students' writings?

2) Do students have favorable attitudes towards the 3 tasks used in the treatment phase?

\section{Review of the Literature}

Recent researches in corpus linguistics analyzing written and spoken academic discourse have established that frequent recurrent sequences of words called lexical bundles are not only salient but also functionally significant (Schmitt, 2004, 2010).

\subsection{Lexical Bundles}

Biber, Johanson, Leech, and Finegan (1999) define lexical bundle as combinations of three or more words which are identified empirically in a corpus of natural language and "show a statistical tendency to re-occur" (p.989). They are also referred to as "clusters" or "chunks and are "extended collocations" which appear more frequently than expected by chance, helping to shape meanings and contributing to our sense of coherence (Hyland, 2008, p.41) The corpusbased studies of Biber et al. (1999; 2004) and Simpson-Vlach and Ellis (2010) have contributed significantly to the understanding of lexical bundle in spoken and written academic discourse. In fact, Biber et al. $(1999,2004)$ and Ellis (1996, 2002a, 2002b) acknowledge specific aspects when identifying lexical bundles in corpora which are frequency, 
range and mutual information score. Based on such studies, it is agreed that LBs have systematic structural and functional characteristics.

\subsection{Structures of lexical bundles}

With regard to their structure, lexical bundles are, in most cases, not complete structural units, but rather parts of phrases or clauses with other fragments embedded in them. Biber et al. (1999) classify them according to several basic structural types depending on the register. For more detail, bundles in conversation are most commonly clausal, of the type pronoun+verb+complement (e.g., I want you to, it's going to be), while in academic prose, most lexical phrases are phrasal, parts of noun phrases or propositional phrases (e.g., as a result of, on the other hand) (Biber et.al (1999). The structural categories corresponding to academic prose are summarized in Table 1.

Table 1. Most Common Patterns of 4-word Bundles in Academic Writing (Biber et al., 1999, pp. 997-1025)

\begin{tabular}{ll}
\hline \multicolumn{1}{c}{ Structure } & \multicolumn{1}{c}{ Examples } \\
\hline Noun phrase + of & $\begin{array}{l}\text { the end of the, the nature of the, the } \\
\text { beginning of the, a large number of } \\
\text { the fact that the, one of the most, the extent } \\
\text { to which } \\
\text { ather noun phrases } \\
\text { at the end of, as a result of, on the basis of, } \\
\text { in the context of } \\
\text { on the other hand, at the same time, in the } \\
\text { present study, with respect to the } \\
\text { Other prepositional phrases } \\
\text { is shown in figure, is based on the, is } \\
\text { defined as the, can be found in } \\
\text { it is important to, it is possible that, it was } \\
\text { found that, it should be noted }\end{array}$ \\
Anticipatory it + verb/adj & $\begin{array}{l}\text { is the same as, is a matter of, is due to the, } \\
\text { be the result of } \\
\text { as shown in figure, should be noted that, is }\end{array}$ \\
likely to be, as well as the
\end{tabular}

\subsection{Functions of lexical bundles}

Previous research studies have also looked into the discourse functions of lexical bundles. By developing a detailed taxonomy, Biber, et al. (2004) found that the three main functions of lexical bundles that serve in discourse entail 1) stance bundles express attitude or assessment, 2) discourse organizers reflect the relationships between different parts of texts, 3) referential expressions refer to physical or abstract entities, or to other textual parts. Each of these main categories has several sub-categories which are associated with more specific discourse functions.

Biber et al.'s (1999) framework has been extended and modified by other authors, notably Hyland (2008). He investigated the frequency, forms and functions of lexical bundles in a large corpus composed of research articles, master's theses and doctoral dissertations from four different disciplines. Hyland's (2008) taxonomy then displayed new categories that better represent the functions of lexical bundles in research writing.

Table 2. Functional classification of lexical bundles in academic writing (Hyland, 2008, pp. 13)

\begin{tabular}{|c|c|c|}
\hline Major functions & Sub-categories & Examples \\
\hline \multirow{5}{*}{$\begin{array}{l}\text { Research-oriented: help } \\
\text { writers to structure their } \\
\text { activities and experiences of } \\
\text { the real world includes: }\end{array}$} & Location : indicating time/place & $\begin{array}{l}\text { at the beginning of, at the same } \\
\text { time, in the present study }\end{array}$ \\
\hline & Procedure & $\begin{array}{l}\text { the use of the, the role of the, the } \\
\text { purpose of the, the operation of } \\
\text { the }\end{array}$ \\
\hline & Description & $\begin{array}{l}\text { the magnitude of the, a wide } \\
\text { range of, one of the most }\end{array}$ \\
\hline & Quantification & $\begin{array}{l}\text { the structure of the, the size of } \\
\text { the, the surface of the }\end{array}$ \\
\hline & $\begin{array}{l}\text { Topic: related to the field of } \\
\text { research }\end{array}$ & $\begin{array}{l}\text { in the Hong Kong, the currency } \\
\text { board system }\end{array}$ \\
\hline
\end{tabular}


Text-oriented : concerned with the organization of the text and its meaning as a message or argument includes:
Transition signals: establishing additive or contrastive links between elements

Signals for results: mark inferential or causative relations between elements

Structuring signals: textreflexive markers which

organize stretches of discourse or direct reader elsewhere in text

Framing signals: situate arguments by specifying limiting conditions

Stance features: convey the writer's attitudes and evaluations

Engagement features: address readers directly on the other hand, in addition to the, in contrast to the

as a result of, it was found that, these results suggest that

in the present study, in the next section, as shown in figure

in the case of, with respect to the, on the basis of, in the presence of, with the exception of are likely to be, may be due to, it is possible that

it should be noted that, as can be seen

\subsection{Construction of Academic voice}

LBs present a key way of shaping texts meaning and contributing to a distinctive and credible academic voice. Many applied linguists and teachers have acknowledged the role of LBs in empowering students' writings by not only finding the right words to express their ideas but by offering specific ways to present those ideas in an impersonal and persuasive style. In this regards, academic writing involves what Ivanic (1998) calls "a discoursal self" (p.336) and what Hyland (2004, p.89) defines as a "professionally acceptable persona" that enables writers to express their attitudes and evaluation towards the content that is expressed. In other words, the term "discoursal self" or the writer's voice refers to the rhetorical forms and features that the students make use of in order to create a professionally credible academic writing related to a specific discipline. In the same vein, Cortes (2004) claims that LBs are intentionally used by professional academic writers to establish solidarity and to distinguish themselves as proficient writers.

Hinkel (2002) and Hyland (2008) content that there is a degree of specificity in the kind of writings that the students are asked to do. Further, Hyland (2008) points out to the disciplinary variation that underlies most specificity. He claims that disciplines are particular ways of using language to participate as group members. In other words, each discipline of hard or soft sciences has its own discourse, presenting conventions and expectations which in turn make texts meaningful. This is acknowledged by Wells (1992: p.290):

\section{Each subject discipline constitutes a way of making sense of human experience \\ that has evolved over generations and each is dependent on its own particular \\ practices: its instrumental procedures, its criteria for judging relevance and \\ validity, and its conventions of acceptable forms of argument. In a word each \\ has developed its own modes of discourse.}

\subsection{Teaching LBs: From theory to Practice}

With the development of the field of linguistics and the computer-based corpus measures, the importance of multi-word expressions or formulaic sequences in language use has been recognized. This has been further stressed by Sinclair (1991)'s idiom principle which offers language users a rich repertoire of multi-word patterns that make up a text. However, multi-word expressions are seldom taught in any principled manner or tested as part of overall vocabulary knowledge. Consequently, there has been little research on the instruction of such patterns. Some applied linguists such as Howarth (1996) and Wray (2000) think that the difficulty in attaining high levels of English proficiency might be attributed to the lack of formulaic sequence learning and use. As an illustration, Irujo (1993) reports that advanced English language learners who made a few grammatical errors knew little about idioms. Similarly, Farghal and Obiedat (1995) found that Arabic speakers who majored in English had little knowledge about collocations in common topics. 
In fact, research on formulaic sequences is lacking, it is not clear whether formulaic sequences is a matter of incidental learning or needs to be taught explicitly. Cortes' (2004) study demonstrates that mere exposure to lexical bundles did not result in students acquiring the knowledge of how to use them. Therefore, as Krashen mentioned (1984, cited in Hirvela, 2004), students are in need of opportunities to practice what has been brought to attention in meaningful communicative tasks. To this point, Hirvela (2004) contends that explicit teaching of rhetorical structures in integrated reading writing activity is effective in students' comprehension and writing. In addition, Jones \& Haywood' (2004) study explores whether such sequences can be successfully taught in explicit way. It was carried out with students who were studying English before entering an English-medium university. They taught formulaic sequences through the highlighting technique during a 10-week course and found that such a method was successful in raising students' awareness of formulaic sequences, but this awareness did not translate into any substantial increase in the usage of the sequences in students' output. The researchers noted, however, that although there was no definite improvement in group performance, "there were instances where individual students used phrases accurately and appropriately in their own unsupported writing" (p. 289)

Boers \& Lindstomberg (2008) have actually researched the effectiveness of pedagogical techniques for multi-word expressions, which in turn has resulted in a number of suggested teaching activities. Hyland (2004) suggests that text analysis is a useful method in developing students' awareness of language structure. He argues that 'consciousnessraising must involve a focus on texts and highlighting the recurrent LBs (p.110). In teaching the structural organization of a particular genre, such as in a definition essay, a discursive essay, providing students with models for text analysis is a good way to start with. It is crucial to raise students' awareness of LBs patterns and their functions in achieving coherent and credible writing. Concept or semantic maps is another good approach to teach LBs. Brown (2007) recommends the use of concept maps as a pre-reading activity as a way to introduce some LBs to students and to highlight how such patterns facilitate the comprehension of the text discourse structure. Such technique is also found to be effective as a post-reading activity, making a paraphrase or a summary of the arguments explained in the text they have just read. Comparing registers is another useful technique that helps students to learn various LBs in spoken as well as written registers. Brown (1994) and Biber (2006) contend that comparing registers raise students' awareness of the difference between spoken and written academic language. In this way, students will be able to express their ideas orally and in written form by using the appropriate lexical bundle.

\section{Methodology}

\subsection{Participants}

The participants of this study consisted of 16 students from the Tunis Business School. They were high-intermediate business learners of English who got admission to the third year and will be asked to carry out a project or research study of approximately 40 pages. Based on their grades of their previous learning experiences, the participants were of similar level of proficiency. They have been taught various business subjects for 3 years, such as: financial English, business English, legal English and commercial English. The researcher contacted the participants, explained to them the purpose of the study and insisted on their commitment to ensure their willingness to participate and finish all the phases of the experimental study. The selection of the participants was based on the reason that they need to develop proficient academic writing related to their specific discipline since it will be necessary for them write short reports, projects and so forth.

\subsection{Design}

The study was based on experimental design that involved the division of the participants into control and experimental groups, administration of a pre-test, implementation of the treatment followed by a post-test and the distribution of a questionnaire. The whole study comprised 11 sessions, each group received 5 sessions using the same materials but proceeding different teaching methods. The teaching sessions were taught three times a week. Each session lasted for one hour and a half. The control group was taught based on a traditional conventional approach of writing while the experimental group received a treatment based on raising-awareness tasks of lexical bundles (LBs). After accomplishing the 10 teaching sessions, the last $11^{\text {th }}$ one was devoted to feedback for the experimental and the control groups. The teaching procedure is clearly explained through the description of the following phases and tasks.

\subsection{Instrumentation}

\subsubsection{Pre-test}

At initial stages of the study, a pre-test was administrated in order to ascertain students' actual knowledge of rhetorical features particularly LBs. The pre-test included 2 short parts. The first part comprised a gap-filling task, where students were provided with some business discipline-specific sentences and they were asked to fill in the blank with the contextually correct phrases, namely LBs such as: is likely to, it is possible that, on the other hand etc. The second part consisted of 2 figures displaying the revenues of Zara Fashion Company from 2003 to 2009. Here the students were asked to describe, compare and interpret the figures. The pre-test was administrated before starting the treating sessions and it lasted around 20 minutes.

\subsubsection{Tasks of the treatment}

Before applying the treatment, the researcher devoted 10 minutes to introduce the idea of rhetorical features particularly the different word sequences and types of LBs so that the students would be familiar with this concept. In order to raise 
students' awareness of the LBs, three possible ways were proposed which are expected to contribute to the teaching of such multi-word expressions.

\subsubsection{Text analysis}

\section{-The selection of the extracts}

To raise students' language awareness, a corpus-based technique was adopted. To this point, 6 authentic short extracts from academic business articles were selected and presented to the participants in each session. More specifically, 3 extracts were taken from the literature review section and the other 3 extracts were selected from the results and discussion section. (Example of the extracts used in session 1 are presented in Appendix A)

The researcher set up specific criteria for the final selection of the extracts. In terms of length, the 3 extracts which are taken from the literature review should have approximately the same number of tokens (150 tokens) and the same case for the extracts taken from the results and discussion section. The second criterion concerns the frequency of some LBs, i.e. the selected extracts should share some recurrent LBs (for example: "on the other hand' in the $1^{\text {st }}$ set of extracts and "the results suggest" in the $2^{\text {nd }}$ set of extracts). The third criteria refer to text readability and content familiarity. To ensure the readability variable, the extracts were read and checked by two other ESP teachers. Similarly, they checked the content of the extracts which should be related to the topics taught in the curriculum of high intermediate business learners of English. Such topics as: Advertising and media, attitudes towards counterfeit products, customer relationship management, e-tourism investment, online banking services, Ford marketing strategies, improving labor market performance, Public-private partnerships...

\section{-The reading activity}

In a collaborative work of 3 pairs composed of 2 students, the experimental group carried out the reading activity. They were asked to read and highlight the LBs found in the extracts and describe their structural patterns. After the identification of the frequently used expressions, the students were asked to answer the questions concerning the authors' main focus and attitudes, and the description of results. In so doing, the students were directed to recognize the functions of the used LBs. Then in order to check the form and meaning of the identified LBs, the students were provided with a List of the structure and functions of most frequent LBs in academic prose adopted from Biber et al. (1999) and Hyland (2008a) (The list is presented in Appendix B). The time alluded to this activity was 40 minutes.

\subsubsection{Gap-filling task}

After the text analysis task, a gap filling activity was presented to students. They were asked to fill in the blank with the contextually appropriate LBs. The content of this activity is related to the specific discipline of the participants. Such activity was employed also in the next sessions. An example of such a task is mentioned in Appendix C. This activity lasted for 10 minutes.

\subsubsection{The writing task}

The purpose of this task is to ensure students' use of recurrent structural patterns (author name + date + introductory verb) and the use of text, research and participant-oriented bundles (on the other hand, the results suggested that, it is possible that...).To illustrate, the students were asked to refer to the one of the extracts (related to literature review or results and discussion sections) and identify authors' main focus and attitudes using their own words, or summarize the findings. This activity lasted for 20 minutes and it was requested that the writings do not exceed 5 lines.

\subsubsection{The post-test}

Upon the completion of all sessions of the treatment, a post-test was distributed to all participants. The purpose of the post test is to analyze students' writings and the use of the LBs (already acquired through the treatment) and compare that with the results of the pre-test. Similarly, the result of the experimental group was compared to that of the control one. The post-test comprised two parts a gap-filling task and a writing task, asking to describe and interpret a figure about the revenues of Benetton Fashion Company and compare it to other companies. The time alluded to this test was 20 minutes and it was done individually.

\subsubsection{The questionnaire}

At the end of the last session and after providing students with the necessary feedback, a formative evaluation was conducted through the use of a questionnaire to elicit students' attitudes towards such activities, and their usefulness in improving their writing. The questionnaire was written in English and constituted of two parts. The first part included 8 items based on a five-point Likert scale ranging from 1 strongly agree to 5 strongly disagree. Those items expressed the participants attitudes towards the various activities carried out in the treatment phase. The second part involved an open-ended question asking students to state how learning LBs made a difference in their writing proficiency. (All items are described in appendix D)

\subsection{Data Analysis}

To interpret the data quantitatively and qualitatively, descriptive analysis for comparing the performance of both groups at the pre-test and post-test were employed. The total score of the tests was 10 points for each. The gap-filling task score was 5 , based on a half point for each correct answer. The writing part, on the other hand, was scored analytically using an assessment checklist which was based on three main aspects: Grammar, coherence and use of LBs. 


\section{Results and Discussion}

\subsection{The effect of consciousness-raising tasks}

The effect of consciousness-raising tasks was measured at two stages, first through comparing the performance of the experimental group in both tests and second through comparing the performance of the experimental and control groups in the post-test.

\subsubsection{Scores of the experimental group}

\subsubsection{Gap -filling tasks}

Within the experimental group, the results suggested a difference in students' scores in the gap-filling tasks. The findings indicated that four students got 5 out of 5 as they answered correctly. The remaining four students, on the other hand got 2 and 3 points out 5 . They misused some LBs, for example, instead of completing sentence " $b$ " with "as reasons of" and "to take advantage of", some of these students selected "as constituents of" and "to save", respectively:

\section{"Lucey (1990) identified the following points as constituents of as reasons of holding} inventories in organization: to absorb variation in demand and production, to meet possible shortage in future and to save to take advantage of bulk purchasing discount."

Moreover, one of these students answered sentence " $e$ " wrongly, instead of using "the process of"; he used "the nature of":

"In order to improve the performance of the organization, the policy was focused on the nature of the process of the delivery rather than the service itself."

There is a possibility that this result is due to students' incomprehension of the whole sentences or lack of attention as the number of LBs provided in the instruction of the task were more than the number of the blanks. The inappropriate use of such expressions may be also explained by students' limited knowledge of some abstract notions used in business discipline as "the process of the delivery or the process of production... After accomplishing the treatment, a post-test was run, and the results were different from the pre-test. In the post-test, all students scored 5 out of 5 in the gap-filling task. In other words, the treatment of LBs was effective in developing the participants' knowledge of some LBs.

\subsubsection{The writing tasks}

Students' writings in the pre-test and post-test were analyzed, compared and evaluated through the use of an assessment checklist. Such evaluation was based on the following criteria: grammar, coherence and LBs use. (The focus was on these criteria only as the content was already provided to students who were just asked to describe and interpret data.)

In terms of grammar, the students' paragraphs in both tests were written correctly in terms of grammatical issues such as spelling, subject-verb agreement and prepositions. As far as coherence is concerned, the results suggested a significant difference between students' writings in the pre-test and the post-test. In the pre-test most students described the provided figure by writing separate sentences indicating the percentage of the results only. For example:

A) The figure shows the revenues of Zara. Zara revenues increased from 2003 to 2009, for example in 2003 the revenues were about 3000 million and it reached 7000 million in 2009. The next figure however shows the revenues of different companies like Inditex, $H \& M$, Benetton and Gap. In this graph the highest revenues were of Gap Company with 12000 million.

On the contrary, the findings of the post test indicated a positive effect of the treatment on 5 writings. In other words, five students of the experimental group showed a significant use of LBs. In their writings, the results of the figure were coherently described and interpreted, using research-oriented text-oriented and participant-oriented bundles. For example:

B) As shown in the figure, the results suggested that the revenues of Benetton have reached different levels of increase. For example, the most important achievement was in 2001 and 2008 with nearly 2,000 million. On the other hand, as compared with other companies, the revenues of Benetton are found to be the least one. This might be explained by other factors such as marketing strategies, price and quality factors.

As implied in example B, the academic voice is reflected in the students' writings through the use of some LBs which were taught during the treatment phase. Thus, this result indicated that the knowledge of LBs within the students of the experimental group had improved their writings significantly. These findings support the notion raised in other research that emphasized the use of LBs in an attempt to construct an academic, research-oriented writing (Biber, 2002, Cortes, 2000, Hyland, 2008) 
On the other hand, the effect of the treatment on the writings of the 3 remaining students' was not of great significance. One possible justification for this is the fact that the experiment was conducted on 10 teaching sessions and those students required more time to be able to retain the various LBs and use them in more different contexts. These results are consistent with those of Jones and Haywood (2004) who discovered that 10-week sessions succeeded in raising students' awareness of formulaic sequences but that awareness did not show an increase in the usage of sequences in students' output.

\subsubsection{Scores: Control vs. Experimental group}

In comparing the writings of both groups, the findings showed that the experimental group outperformed the control group particularly in the writing task. The writing style of the students of the experimental group showed a significant difference in both tests. The treatment enabled them to expand their repertoire of academic rhetorical features to include LBs and so to write coherent paragraphs with an impersonal voice. To illustrate, they used attitudinal stance "might be explained by" to express their attitudes towards the results. They also employed discourse organizing to signal that a point of contrast will be introduced "on the other hand" "as compared with".

In the control group, however, the students did not show much development in terms of the writing style. Their writings in the post test remained more or less the same as in the pre-test. Nevertheless, what is surprising in the findings is that 3 students of the control group used specific LBs without being explicitly taught about that. Here, the possible interference of students' level of proficiency cannot be denied. Such use of LBs within the control group is correlated with their good level of proficiency as mentioned through their university grades. Also, such result may be explained by students' good retention of such LBs as they noted their recurrence in many readings. The following sentence is an illustration of LBs used in a student's writing of the control group:

"As seen in the graph, it is clear that Benetton revenues have witnessed an increase, but still that was lower when compared with Zara and Gap companies."

\subsection{Students' attitudes towards the tasks}

The evaluation questionnaire was designed with a combination of five-point Likert scale items and an open-ended question. It was distributed in an attempt to elicit students' attitudes towards the usefulness of the tasks and how that made a difference in their writing proficiency. The following figure shows some interesting patterns, the most intriguing of which is that in these items the students revealed quite different perceptions towards the tasks of the treatment.

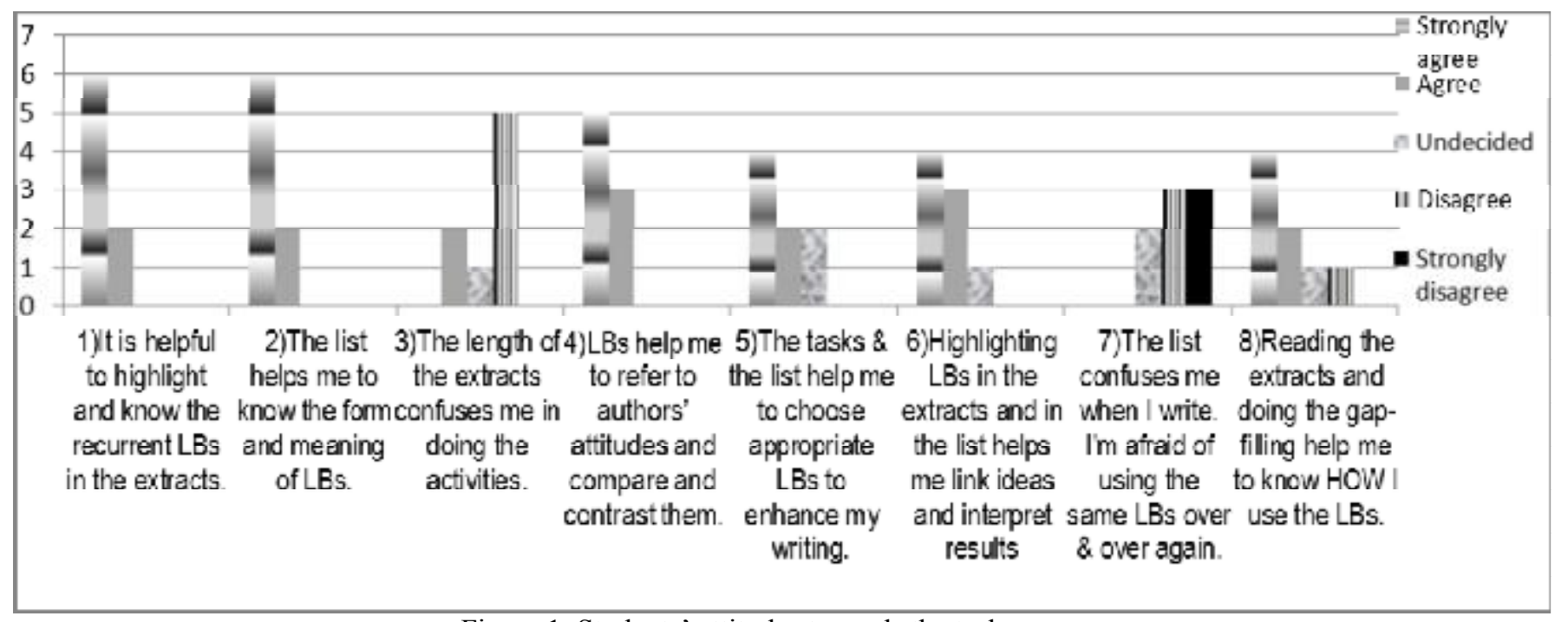

Figure 1. Students' attitudes towards the tasks

Concerning the reading and gap-filling activities, most students of the experimental group agree and strongly agree with items 1, 4, 6 and 8 suggesting that highlighting the recurrent LBs in the extract helped them to notice those expressions and know their functions, fill in the blanks correctly, find out authors' point view and interpret the results. Such finding support Biber, Conrad \& Reppen (1998) who put an emphasis on the importance of the corpus-based approach in analyzing language use which in turn established the significance of LBs. Nevertheless, 2 students found the extracts a little bit long, and so they were not totally concentrated to carry out the whole activity.

As regard the use of the LBs list, most students agree and strongly agree on the usefulness of LBs list in enhancing their writings. They indicated that the list helped them to choose the appropriate expressions to link their ideas and interpret results. Such result confirms the claims made by Biber et al., (1999), Cortes (2004) and Hyland (2008) in their previous studies where they acknowledged the fundamental role of LBs in developing the rhetorical style of the writing. However, about 2 students disagreed on this point, suggesting that the number and types of the LBs in the list confused them when writing. A possible explanation for this result might be because of students' fatigue to concentrate and accomplish the last writing activity or because of time constraints. 
In answering the open-ended question, most students, in particular those who got good scores in the post-test, admitted the significant difference between their writings in the pretest and those in the post-test. To illustrate, one of them mentioned that the use of LBs directed him in writing by stating the purpose of the paragraph, i.e comparing and contrasting attitudes or describing results. He further stated that his writing of the post-test was enriched with different linking expressions that were not written repeatedly as he did in the writing of the pre-test.

\section{Conclusions}

\subsection{Summary of the findings}

The present study was an attempt to investigate whether Lexical Bundles (LBs) awareness had any impact on writing proficiency of Tunisian intermediate ESP language learners. It also sought to investigate learners' attitudes towards the used LBs tasks. To this purpose, a control group and an experimental group were selected; the first group was taught on the basis of traditional approach. The other group was taught through consciousness-raising tasks involving highlighting recurrent LBs, referring to the list, and using such LBs in the writing task. Next, the activities of the post test were scored and the writings were analyzed and compared through the use of an assessment checklist.

The results showed that there was a significant improvement in the participants' writings in the post-test when compared with the pre-test. Their writings in the post-test reflected an academic voice including attitudinal and evaluative stance. The results also suggested students' positive attitudes towards the activities of the treatment in raising their awareness of the fundamental role of LBs in academic writing. On the other hand, only few students who disagreed with the use of LBs List and they perceived the extracts as long to read and answer the questions.

\subsection{Limitations of the study}

In terms of research design, the reading and gap filling activities yielded only a partial picture of students' appropriate use of the various lexical bundles (LBs). The use of concept or semantic maps and register comparison (written vs. spoken or academic vs. popular writing) would have provided a more comprehensive and natural view of different types of academic and discipline-specific LBs used by students.

In the same vein, there are some affective and personal trait variables that were unaccounted for in the analyses which may predict the appropriate use of LBs, such as: students' level of motivation in the writing skill, students' proficiency level in the reading and writing skills, students' linguistic competence of vocabulary and specific-phrases knowledge...

Another area of concern that limits the strength of the findings relates to the representativeness of the sample. Clearly, the study was based on a small sample and limited number of teaching sessions. As a consequence, it is difficult to generalize the findings. Further studies in teaching LBs with a large sample and in a long period of time instead of 10 sessions would lead to more significant results. Finally, the use of more sophisticated tools to analyze the data of a large sample could have yielded more revealing findings.

\subsection{Implications}

In spite of its limitations, the present study contributed to a number of pedagogical implications. One of the most is the crucial need for a suitable pedagogical approach of teaching LBs in an attempt to effectively equipping students to read with comprehension and write with persuasion.

On the basis of the results of the present study, teaching LBs is an important endeavor to reach proficiency in academic writing. They have to be taught explicitly through various techniques and different subjects. In other words, teaching LBs is recommended not only in writing courses but also in other discipline-specific courses and should be included in the criteria of evaluating compositions and tests. For example, in teaching commercial English for business learners of English, the tests should not only include definitions or matching tasks but also a question which requires students' critical production where the persuasive rhetorical style would be reflected through the use of LBs. In addition, in the speaking and listening skills, teachers should raise their students' awareness of other specific LBs used in the spoken register and their significance in attaining good levels of oral proficiency.

\section{References}

Biber, D. (2006). University language. Amsterdam: John Benjamins.

Biber, D. \& Barbieri, F. (2006). Lexical bundles in university spoken and written registers. English for Specific Purposes. 26: 263-286.

Biber, D., Conrad, S. \& Cortes, V. (2004). "If you look at ...": Lexical bundles in university teaching and textbooks. Applied Linguistics, 25: 371-405.

Biber, D., Johansson, S., Leech, G., Conrad, S. \& Finegan. E. (1999). Longman grammar of spoken and written English. Harlow, UK: Pearson Education.

Brown, C. L. (2007). Strategies for making social studies texts more comprehensible for English-language learners. The Social Studies, (September-October), 185-188.

Brown, H. D. (1994). Teaching by principles: An interactive approach to language pedagogy. New Jersey: Prentice Hall Regents. 
Boers, F., \& Lindstromberg, S. (2008). From empirical findings to pedagogical practice. In F. Boers \& S.

Lindstromberg (Eds.), Cognitive linguistic approaches to teaching vocabulary and phraseology (pp. 375-393). Berlin, Germany: Mouton de Gruyter.

Cortes, V. (2004). Lexical bundles in published and student disciplinary writing: Examples from history and biology. English for Specific Purposes, 23: 397-423.

Cortes, V. (2006). Teaching lexical bundles in the disciplines: An example from a writing intensive history class. Linguistics and Education, 17(4): 391-406.

Ellis, N. C. (1996). Sequencing in SLA: Phonological memory, chunking, and points of order. Studies in Second Language Acquisition 18 (1): 91-126.

Ellis, N. C. (2002a). Frequency effects in language processing: A review with implications for theories of implicit and explicit language acquisition. Studies in Second Language Acquisition, 24(2): 143-188.

Ellis, N. C. (2002b). Reflections on frequency effects in language processing. Studies in Second Language Acquisition, 24(2): 297-339.

Ellis, N., Simpson-Vlach, R. \& Maynard, C. (2008). Formulaic Language in Native and Second-Language Speakers: Psycholinguistics, Corpus Linguistics, and TESOL. TESOL Quarterly, 42(3): 375-96.

Farghal, M., \& Obiedat, H. (1995). Collocations: A neglected variable in EFL. International Journal of Applied Linguistics, 28, 313-331.

Hinkel, E. (2002). Second language writers' texts. Mahwah, NJ: Erlbaum.

Hirvela, A. (2004). Connecting reading \& writing. Michigan: University of Michigan Press.

Howarth, P. (1996). Phraseology in English academic writing: Some implications for language learning and dictionary making. Tubingen, Germany: Max Niemeyer.

Hyland, K. (2004). Disciplinary discourses: Social interactions in academic writing. Ann Arbor: University of Michigan Press.

Hyland, K. (2004). Corpus analysis and academic persuasion. In U. Conner \& T. A. Upton (Eds.), Discourse in the professions: perspectives from corpus linguistics.

Hyland, K. (2008). As can be seen: Lexical bundles and disciplinary variation. English for Specific Purposes, 27: 4-21.

Hyland, K. \& Tse, P. (2005). Hooking the reader: A corpus study of evaluative that in abstracts. English for Specific Purposes, 24(2): 123-139.

Hyland, K. \& Tse, P. (2007). Is there an 'academic Vocabulary'? TESOL Quarterly, 41(2): 11-25.

Irujo, S. (1993). Steering clear: Avoidance in the production of idioms. International Review of Applied Linguistics in Language Teaching, 31, 205-219.

Ivanič, R. (1998). Writing and identity: The discoursal construction of identity in academic writing. Amsterdam: John Benjamins.

Jones, M., \& Haywood, S. (2004). Facilitating the acquisition of formulaic sequences: An exploratory study in an EAP context. In N. Schmitt (Ed.), Formulaic sequences (pp.269-292). Amsterdam, the Netherlands: John Benjamins.

Lau, H. H. (2004). The structure of academic journal abstracts written by Taiwanese PhD students. Taiwan Journal of TESOL, 1(1), 1-25.

Schmitt, N. (ed.). (2004). Formulaic sequences. Amsterdam: Benjamins.

Schmitt, N. (ed.). (2010). Researching Vocabulary. Palgrave, Macmillan.

Schmitt, N. (2010). Researching vocabulary: A vocabulary research manual. Basingstoke, England: Palgrave Macmillan.

Scott, M. \& Tribble, C. (2006). Textual patterns. Amsterdam: Benjamin.

Simpson Vlach, R. \& Ellis, N. C. (2010). An Academic Formulas List: New Methods in Phraseology Research. Applied Linguistics, June 22. Republication draft

Sinclair, J. (1991). Corpus, concordance, collocation. Oxford: OUP.

Swales, J. M. (1990). Genre analysis: English in academic and research settings. Cambridge: Cambridge University Press.

Wells, G. (1992). The centrality of talk in education. In K. Norman (ed.), Thinking voices: The work of the national oracy project. London: Hodder and Stoughton.

Wray, A. (2000). Formulaic sequences in second language teaching: Principle and practice. Applied Linguistics, 21, 463-489. doi:10.1093/applin/21.4.463 